\title{
Certezas e incertidumbres en el espacio de la Antropología Aplicada
}

\section{Certainties and Uncertainties in the Space of Applied Anthropology}

\author{
Alejandro ISLA \\ FLASCO Argentina \\ aleisla@retina.ar
}

Recibido: 31 de enero de 2014

Aceptado: 12 de junio de 2014

\begin{abstract}
Resumen
La antropología desde sus orígenes — más allá de sus encomiables fines científicos- estuvo involucrada en política públicas nacionales en relación a la dominación de territorios, recursos naturales, fuerza de trabajo y culturas. Su rol nunca fue acrítico de su papel, sino que al calor de esas prácticas, produjo reflexiones básicas para la crítica del colonialismo en espacios lejanos a la tradición de Occidente, donde nació. La antropología social en Argentina no es ajena a esta trayectoria. Pero a partir de fines de 1960 pasó a involucrarse — con discontinuidades, marcadas por dictaduras - en políticas públicas y en procesos de desarrollo en comunidades rurales. El artículo además de reseñar esa trayectoria de compromiso con lo 'aplicado', propone discutir apoyado en 'un caso', 3 aspectos teóricos centrales : 1) las relaciones de poder y cultura en los procesos de desarrollo desde que se acuñó el término "colonialismo interno"; 2) el papel del antropólogo en la construcción del 'sujeto colectivo de proyecto', o las formas de gestionar la participación de los 'supuestos beneficiarios' en la elaboración, participación y control de proyectos de desarrollo localizados, como de políticas públicas; y 3) la indispensable necesidad de introducir el trabajo interdisciplinario y la construcción de equipos, tanto para las evaluaciones de políticas públicas, como para su elaboración y análisis contextual, donde la cultura política de las instituciones, como de la sociedad local, juegan un rol fundamental. En el artículo se debaten estas cuestiones teórico-metodológicas sobre un proyecto de desarrollo en el noroeste argentino, cuyos ecos llegan hasta el presente.
\end{abstract}

Palabras clave: Antropología; Antropología Aplicada; Desarrollo; Política; Intervenciones Sociales.

\begin{abstract}
Since its origins, Anthropology - beyond its commendable scientific purposes - was involved in national public policies in relation to the domination of territories, natural resources, labor and cultures. His role was never uncritical of these targets; on the contrary, it resulted in basic practices and ideas to criticize colonialism in traditions outside the Western Civilization, where Anthropology was conceived. The development of Social anthropology in Argentina is far from this trayectory. Nevertheless, from late 1960 onwards, it begun to be engaged in public policies and development processes in rural communities - with discontinuities shaped by different dictatorships. In this article, I will review the brief history of the applied
\end{abstract}


anthropology in Argentina and I will discuss the theoretical and methodological issues of a project developed in an Indian rural community in northwestern Argentina, whose echoes remains until today. Based on this case study, the aim of this article is to discuss the following theoretical aspects: 1) the relationship of power and culture inside process of development, especially since the term "internal colonialism" was coined; 2) the role of the anthropologist in the construction of 'the collective subject of a project', or the ways of managing the participation of the 'intended beneficiaries' in the development, participation and control of particular development projects, as well as public policies; and 3) the imperative need of putting at the front row of public policies' contextual analysis, inception and evaluation the interdisciplinary work and team building. It is in this context where the political culture of the local society and institutions plays a fundamental role.

Keywords: Anthropology; Applied Anthropology; Development; Politics; Social Interventions.

Referencia normalizada: Isla, A. (2014). Certezas e incertidumbres en el espacio de la Antropología Aplicada. Revista de Antropología Social, 23, pp. 91-116.

SUMARIO: 1. Introducción. 2. Reseña de una subdisciplina. 3. Diferentes posturas de la antropología sobre su aplicación. 4. El proyecto Amaicha de desarrollo integrado. 5. La importancia de la teoría en la antropología aplicada. 6. Reflexiones finales 7. Referencias bibliográficas.

\section{Introducción}

En este artículo se abordan tres aspectos teórico-metodológicos de la actividad de la antropología en relación a las políticas públicas y al desarrollo que advierto como importantes a lo largo de mi experiencia en la materia y que han generado debates, muchos de ellos inconclusos. Considero a la antropología aplicada — vinculada directamente a la formulación, gestión y ejecución de proyectos de desarro1lo, como a la evaluación de políticas públicas y actividades de consultoría - como subdisciplina de la antropología social, ya que requiere nutrirse tanto de sus posturas teóricas, como metodológicas.

En primer lugar me concentraré en la necesidad de que la antropología considere relevante la economía política del desarrollo y de las políticas públicas. Existen en antropología diversas posturas respecto a su relación con el desarrollo - y la filosofía que lo sustenta - en tanto cúmulo normativo de acciones de intervención para la gestión de cambios/ mejoras en las condiciones de vida de poblaciones de diversas etnias.

Señalaré los motivos por los cuales el vínculo entre antropología y desarrollo ha sido históricamente complejo. Para ello describo los procesos de desarrollo en tanto arena política en la que confluyen diversos actores: beneficiarios, técnicos, financiadores, políticos locales, y también los/las antropólogos/as. Sus relaciones incluyen rechazos, negociación, acomodación y resistencia. Una mirada que privilegia lo político supone dar cuenta de las posiciones desiguales en las que se encuentran esos diversos actores en un escenario de desarrollo, cada uno con tácticas y estrategias de las que se valen para lograr sus objetivos, a menudo, contrapuestos. El resultado de tal interacción no es el mismo a lo largo del ciclo de proyecto, sino que por el 
contrario, sufre marchas y contramarchas, produciendo resultados inesperados que no fueron pensados previamente.

En segundo lugar, refiero a la necesidad del imperioso reconocimiento de las relaciones de poder y cultura política — por encima de procedimientos y dispositivos tecnológicos que exigen los procesos de desarrollo, como en el diseño y aplicación de políticas públicas. Estos procesos y políticas deben ser entendidos dentro de un campo de intereses y fuerzas - muchas veces cambiantes - en el que el/la antropólogo/a está involucrado, más allá de su voluntad. Fuerzas e intereses con los que debe lidiar, negociar y en consecuencia, saber descifrar permanentemente. Dado que el papel tradicional del antropólogo/a está fuertemente ligado a diferentes tipos de poblaciones subalternas, - periféricas a formas del capitalismo dominante y de las culturas oficiales - el análisis de la cultura política de dichas poblaciones es central. Pero al mismo tiempo es central tomar en cuenta la cultura de las instituciones involucradas y la conformación histórica-étnica del Estado nacional. Al resaltar el costado político de las prácticas de los actores (beneficiarios, técnicos, antropólogos, etc.) involucrados en un proceso o política concreta, se les confiere agencia en la teoría que aquí se sustenta; además de observar el proceso específico dentro de un entramado de relaciones dinámicas insertas en un contexto socio-político.

Esto lo relacionaré con el papel que asigno al antropólogo involucrado en un proceso específico de desarrollo, a 'la construcción del sujeto colectivo de proyecto', que requiere de varias etapas. Proceso que implica las formas de hacer sociedad, promocionar y gestionar la participación organizada de los beneficiarios en la elaboración, control y dirección de proyectos de desarrollo localizados, así como el impulso a su organización política/territorial, frente a políticas públicas que los tienen por 'población objetivo'. Soy consciente de la postura ideológica que sustenta lo dicho, aunque trataré a lo largo de este texto de darle una explicación no-ideológica, articulando varios niveles de las ciencias sociales. Además, ilustro estas cuestiones con la presentación resumida de un caso paradigmático - por los debates académicos y controversias técnicas entre diferentes especialistas que generó en Latinoamérica-, cuyos ecos llegan hasta el presente.

Por último, trato la necesaria formación interdisciplinaria que la antropología debe brindar en el terreno aplicado, en la construcción de equipos, tanto evaluaciones de políticas públicas, como para su elaboración y análisis contextual, donde la cultura política de las instituciones, como de la sociedad local, juegan un rol fundamental. Pero antes que nada presento un breve boceto del surgimiento de la sub disciplina.

\section{Reseña de una subdisciplina}

La antropología aplicada ${ }^{1}$ tiene en Argentina un nacimiento reciente, y como su madre - la Antropología Social — ambas carecen de una tradición disciplinar como

${ }^{1}$ Como se la denomina en amplios círculos profesionales, recibiendo otros nombres de acuerdo al momento histórico y al lugar geográfico: antropología 'de acción', 'de gestión' o ‘para el desarrollo' refieren más o menos a la misma cosa. Me referiré indistintamente a antropología de intervención o antropología aplicada. 
pueden exhibir en el país otras ciencias sociales (verbi gracia la sociología, la historia y la psicología). Esto es así porque la Argentina a pesar de inventarse como país moderno, urbano e industrial, relegó las culturas de los pueblos originarios a la etapa del salvajismo y destinó su estudio a la arqueología y al folklore. Entre los mitos fundadores de la nación en el XIX, el 'salvajismo' de los pueblos originarios debía considerarse una rémora del pasado, que durante el siglo XX fue abordado por folkloristas, en su mayoría cultores del pintoresquismo. En aquella mitología fundante del Estado nacional, se postulaba que el verdadero problema de la Argentina moderna era 'el bárbaro', encarnado en el gaucho, o sea en el criollo. Argentina se imaginaba como país europeo, 'sin indios' y con el único obstáculo del criollo para su pleno desarrollo. Entonces, urbano e industrial, el país era campo para estudios sociológicos que se fueron desarrollando durante el XX.

La Antropología en estos parajes — pensada sobre culturas fuera del círculo occidental como su objeto exclusivo - fue relegada por corrientes, que como la 'histórico cultural', fueron arrastradas a las costas del Rio de la Plata por académicos italianos y austríacos, portadores de ideologías totalitarias, que adaptaron perfectamente la Antropología a las variantes del positivismo local que había florecido a finales del siglo XIX. La antropología social, como tal, comienza con sus primeros pasos vacilantes en el país a mediados de la década del sesenta del siglo pasado. Su desarrollo sin embargo, no fue continuo: perseguida por las dictaduras y los períodos convulsionados que asolaron a la Argentina durante casi cincuenta años, interrumpiendo la vida universitaria y académica por lapsos prolongados. En aquellos años Hugo Ratier (1972) iniciaba su trabajo de campo en villas miserias del Conurbano Bonaerense; Santiago Bilbao (1975) en el Instituto Nacional de Tecnología Agropecuaria (INTA) estudiaba asociaciones campesinas y conformaba cooperativas de producción algodonera en provincias del norte del país ${ }^{2}$. Eduardo Archetti y Kristi Anne Stölen (1975) comienzan en 1972 sus trabajos de campo entre campesinos/ colonos inmigrantes del norte de la provincia de Santa Fe, publicando una obra de referencia para la antropología económica. Edgardo Cordeu (1967) y Alessandra Sigfredi $(1971)^{3}$ emprendían etnografías entre los pueblos Tobas y Pilagas de las provincias de Chaco y Formosa; los hermanos Bartolomé (1969) también analizaban aspectos de la estructura social en asentamientos Toba en la región chaqueña y Esther Hermitte regresaba de Chicago en 1965 — después de obtener su doctorado con su tesis sobre comunidades mayas de Chiapas, para iniciar estudios de cooperativas de tejedoras en el noroeste argentino. En estos emprendimientos descoordinados entre sí, se encuentran los inicios de la antropología social y las primeras semillas de una

${ }^{2}$ Bilbao participó en la redacción de numerosos informes técnicos sobre evaluación de propuestas como fue el caso de los asentamientos indígenas y criollos en el norte argentino en relación al uso y producción de recursos naturales, sus formas de asociación, las relaciones de clase social en las que estaban insertos, etc. También publicó algunos artículos en aquella época (Bilbao, 1975).

${ }^{3}$ Esta referencia se trata de una obra escrita por Edgardo Cordeau y Alessandra Sigfredi (ver bibliografía). 
antropología aplicada en Argentina, que recién se fortalecería lentamente, al término de la última dictadura militar (1976-1983).

En esos inicios, las primeras semillas de 'la aplicada' fueron dos: el trabajo de Bilbao con las cooperativas de Santiago del Estero y Tucumán en el INTA y el estudio de diagnóstico y propuestas de desarrollo agropecuario, salud y educación, que realiza Esther Hermitte ${ }^{4}$ (1994) dirigiendo un complejo equipo interdisciplinario del Centro de Estudios Sociales (CIS) del Instituto Di Tella de aquella época. En 1969 el CIS ganó una licitación convocada por el Consejo Federal de Inversiones ${ }^{5}$ requerida por la provincia de Chaco, para realizar un estudio sobre poblaciones de los grupos étnicos Qom (Toba) y Wichí, y realizar propuestas para su "integración a la sociedad nacional". La dirección del CIS, al ser un 'estudio sobre indios', no dudó que un antropólogo debía dirigirlo y así Hermitte quedó frente a lo que sería un equipo de abogados, economistas, politólogos, sociólogos, demógrafos, urbanistas de primera línea en sus disciplinas. Para cumplir con el objetivo del estudio los/las antropólogos/as realizamos ${ }^{6}$ un intenso trabajo de campo en tres asentamientos Qom y en uno Wichí del Chaco. Estos trabajos fueron monitoreados por diferentes miembros del equipo de dos maneras: por un lado la lectura de las 'notas de campo' que los/ las antropólogos/ as debíamos realizar en varias copias y por otro, con algunas visitas al terreno y discusión in situ.

Me detengo en esta breve reseña de la experiencia pues marcará un hito en la antropología aplicada en Argentina, a pesar de que Hermitte tuvo que lidiar con tensiones e intereses externos e internos al CIS y al equipo. Pero justamente, el pulso mantenido con esas fuerzas es una de las características centrales de los proyectos aplicados. En efecto, el título mismo de la convocatoria - Estudio sobre la situación de los aborígenes de la Provincia del Chaco y políticas para su integración a la sociedad nacional - era profundamente molesto para los antropólogos, como para la mayoría de los otros científicos sociales convocados. Eran épocas en las que en América Latina se discutía la teoría de la dependencia, la pedagogía del oprimido y 'las vías' de transformaciones sociales profundas. Es así que el objetivo del estudio, diseñado y solicitado por el ejecutivo de la provincia de Chaco, originó un prolongado debate en el equipo que quedó plasmado en la introducción de esos tomos? Se rechazaba la idea de 'integración' puesto que se demostraba que a esa altura del siglo XX los Qom, como los Wichí, habían pasado ya por varias fases de integración a un 'capitalismo dependiente'. Y además, el término "integración” se basaba en los supuestos de que aquellos abandonaran lo que les quedaba de su cultura originaria

${ }^{4}$ El estudio de campo se realizó en 1970, entregándose el informe al CFI en 1971. La Editorial de la Universidad Nacional de Misiones publicó los 3 tomos, con agregados y adendas, recién en 1994.

${ }^{5}$ Entidad autárquica nacional de desarrollo que presiden representantes de las provincias. Realiza estudios y propuestas de desarrollo por requerimiento de cada provincia.

${ }^{6}$ Participé en los intensos trabajos de campo en un asentamiento Toba rural (Cabá Naró, en Departamento de Trés Isletas) en el medio de la provincia del Chaco, y en una villa miseria Toba en la periferia urbana de Resistencia (capital) de esa provincia.

${ }^{7} \mathrm{El}$ "Estudio..." citado anteriormente se editó como informe en 1971 y luego en 3 tomos en 1994 por la Univ. Nacional de Misiones, Argentina; ver Bibliografía: Hermitte [1971] 1994. 
(entre otros aspectos, la lengua). Destaco aquel debate por tres cuestiones: en primer lugar, la necesidad de discusión teórica para formular marcos que orientaran las acciones propuestas y guiaran los trabajos de campo en situaciones pluriétnicas; ello nos alejaba - a los antropólogos - de una etnografía ingenuamente empirista. En segundo lugar, se discutió teóricamente y con mucha información de campo, las relaciones entre las clases sociales en la periferia con los grupos étnicos, concluyendo en la imposibilidad de subsumir mecánicamente la 'diferencia y conflictividad étnica' a la 'diferencia y conflictividad social'. Por último, el debate nos abría a una serie de trabajos que estaban iluminando distintas rutas en el continente, como las obras de Eric Wolf (1972) ${ }^{8}$, Darcy Ribeiro (1972), González Casanova (1969), Stavenhagen (1969). Las dos últimas, proponiendo un concepto teórico que hasta el presente requiere de una reflexión profunda en el continente: el concepto de 'colonialismo interno"s.

Dejando algunas contribuciones en el recorrido, dado el espacio del artículo, salto a los años recientes ${ }^{10}$, cuando se creó en el año 2009 el Laboratorio de Antropología Aplicada y Políticas Públicas (LAB), en la Facultad Latinoamericana de Ciencias Sociales (FLACSO-Argentina), dentro del área de Antropología Social y Política de esa institución. El LAB realiza dos actividades: formación de recursos humanos en el ámbito de la antropología social y de las políticas públicas, enfatizando el rol de la antropología social en el mismo; y análisis y evaluación de políticas públicas. Para ello ha conformado equipos con estudiantes de postgrado, produciendo diversos informes, con aportes teórico-metodológicos ${ }^{11}$.

\section{Diferentes posturas de la antropología sobre su aplicación}

En las postrimerías del siglo XX, varios antropólogos (Grillo, 1985, 1997 y Escobar 1995, 1997, entre otros), coincidieron en la existencia de dos corrientes de pensamiento sobre el desarrollo que denominaron: antropología para el desarrollo por un lado, y por otro, antropología del desarrollo por otro. La primera, relacionada con la aplicación de la antropología en proyectos de desarrollo, proponiendo un compromiso activo con comunidades, barrios, tribus — a menudo consideradas 'vulnerables' y 'tradicionales' en los diagnósticos previos-, con el objetivo de transformar sus instituciones 'tradicionales' desde su interior (Escobar, 1997). La

\footnotetext{
${ }^{8}$ De su vasta obra, para la época que estoy tratando, cito en las referencias dos emblemáticas: 1967 y 1972.

${ }^{9}$ Una vez liberadas las nuevas repúblicas de su dominación externa en el XIX, los procesos económicos, políticos y culturales en los que se había basado aquella dominación quedaron en parte impresos en las nuevas estructuras estatales que surgieron, en las elites que construyeron las nuevas instituciones, pero también de la sociedad en su conjunto. El mote de 'salvajes' o 'bárbaros' fue reutilizado por las clases dirigentes que se pintaron de 'europeas' para 'civilizar' a sectores subalternos, siempre estigmatizados.

${ }^{10}$ Trato en el apartado 3 el caso emblemático de Amaicha, comunidad de Calchaquíes que comenzó en 1986.

${ }^{11}$ La Doctora en Antropología (Sorbonne Nouvelle-Paris 3) Nathalie Puex dirige el LAB, con un equipo de postgraduados en antropología social. Las actividades del LAB se pueden ver en http://www.asyp.org.ar/lab
} 
antropología del desarrollo en cambio, propone el distanciamiento absoluto del antropólogo/a de cualquier forma de intervención (ibid.) y sugiere tomar como objeto de análisis a las prácticas de desarrollo, en tanto procesos socio-políticos y económicos.

Desde su origen, la teoría del desarrollo ha sido elaborada desde modelos economicistas y tecnocráticos sin tener en cuenta los aspectos sociales y culturales de las sociedades históricas. Esto resultó en innumerables fracasos, ya sea por inadecuación de las propuestas, desinterés de los beneficiarios o por causar modificaciones perjudiciales. Los contundentes fiascos causados por un tipo de planificación 'verticalista' y una mirada sobre lo local desde un 'zepelín', exigieron un replanteo de esos modelos desde mediados de los setenta. Los proyectos comenzaron a atender a los factores sociales y buscaron ser culturalmente viables. Pero también fueron más sensibles a las iniciativas y propuestas de la población 'beneficiaria', sosteniendo paulatinamente que los actores implicados participaran no sólo en el diseño, sino también en la gestión, dirección y evaluación de los programas de desarrollo. Esta nueva forma de encarar esos proyectos creó una importante demanda de antropólogos para recabar aspectos sociales y culturales de los grupos 'beneficiarios', así como evaluar las consecuencias de las transformaciones que se planificaban. Fue el impulso definitivo de la antropología para el desarrollo; o aplicada, para mi gusto.

La antropología del desarrollo en cambio, se presenta como un campo fértil de análisis que varios antropólogos tomaron como nicho de especialización, ligado a la economía política. Existen unos cuantos trabajos etnográficos en los que se analiza con profundidad las relaciones sociales y los conflictos de poder que se presentan entre los diferentes actores que participan en proyectos de desarrollo. También hay etnografías de las agencias de desarrollo, de las entidades financiadoras, de la construcción del 'otro' en estas relaciones complejas, de cómo afectan las transformaciones a los 'beneficiarios', de qué manera son involucrados. Un ejemplo de ello fue la obra clásica de Ferguson (1990) que analiza un caso de desarrollo rural financiado por el Banco Mundial en Lesotho. O el intento de Mathwes (1997) sobre Amaicha (Argentina), que retomo en el análisis de caso en el siguiente apartado.

Cualquiera sea la participación de antropólogos en la antropología para el desarrollo, deben partir necesariamente de un supuesto previo que es el siguiente: "no cuestionar la necesidad general del desarrollo sino tomarlo como un hecho inevitable y como una situación real ineludible" (Escobar, 1997: 6). En cambio, en el caso de la antropología del desarrollo se parte de una postura crítica al desarrollo y a las prácticas relacionadas. Ambas propuestas se construyen desde supuestos teóricos diferentes.Esta división entre antropología 'para' y antropología 'del', sólo parece analíticamente útil para entender algunas de las disputas que se han dado a lo largo de la historia de la disciplina entre detractores hipercríticos del desarrollo y sus defensores más tenaces. Algunos de los detractores, que además se adhieren a esa división, escriben desde una visión crítica de la macroeconomía del desarrollo ${ }^{12}$. Pero en

${ }^{12}$ Especialmente las determinaciones que provienen del ambiente ideológico en el cual se planifican los modelos y ejecutan los proyectos de desarrollo, por ejemplo, el ambiente neoliberal 
el caso de Escobar (1997), dirige sus críticas más como filosofía modernizadora y civilizadora ${ }^{13}$ producida por Occidente, que en referencia a proyectos en particular. Los trabajos de Escobar resultan interesantes en términos de una economía política del desarrollo, pero al no estar centrados en el trabajo de elaboración y ejecución de proyectos con todas sus dificultades, sus apreciaciones a veces resultan críticas sólo ideológicas, y generalizaciones al juzgar todas las intervenciones de desarrollo como idénticas. No distingue especificidades, tampoco los diversos actores que demandan el desarrollo. Sin desmerecer su trabajo, que pone en debate esa actividad, quiero rechazar el fundamento epistemológico que subyace bajo la escisión entre antropología 'del' y 'para', sosteniendo que el/ la antropólogo/ a involucrado/ a en uno de esos proyectos o en una política pública — cualquiera sea su rol-debe tener una sólida formación en teoría social y economía política para saber dónde se encuentra situado.

Como sabemos, no existe una única noción de desarrollo, pues al resultar de una construcción social e histórica, es un concepto dinámico, polisémico y por añadidura, polémico (Monreal y Gimeno, 1998). Algunas características epistemológicas y de índole político-ideológica que conlleva el desarrollo - agravadas en el espacio de intersección con la antropología - son importantes de puntualizar.

Una primera característica que enfrenta el concepto de desarrollo es su carácter teleológico ${ }^{14}$ en el sentido de que tal y como es planteado usualmente, el desarrollo se refiere a un estado de cosas deseable, ideal, al que es esperable llegar. Según Oszlak (entrevista de Nicandro Cruz, 2001), la visión de sociedad ideal que el concepto evoca, si bien no es objetable científicamente, lo convierte en una meta a alcanzar frente a una realidad que sólo se define por la falta de desarrollo, que sólo muestra 'sub' o ausencia de desarrollo. Oszlak agrega que "si intentáramos medir su grado de realización histórica, solo podremos apelar a indicadores que apenas consiguen establecer posiciones a través de un ranking de sociedades humanas" (ibíd.).

Un segundo aspecto relacionado con la característica finalista de la noción, es que el desarrollo está inextricablemente ligado a la idea de 'progreso', como esencia de 'civilización'; ideas centrales en la expansión y hegemonía de Occidente, basadas en la necesidad de superar lo que se calificaba desde las metrópolis como salvajismo y barbarie. Estas nociones tan enraizadas en la historia y el alma de Occidente constituyen hasta nuestros días el leit motiv de la crítica antropológica contra el etnocentrismo ${ }^{15}$. La búsqueda de 'mejores condiciones' de vida para poblaciones y culturas relegadas, es pensada y formateada desde las metrópolis, lo que implica una

que gobierna los organismos multilaterales, incluyendo la Comisión Económica para la América Latina (CEPAL) después del Consenso de Washington (1989).

${ }^{13}$ Con todo el significado que dentro de la antropología en sus estudios postcoloniales se le asignan a esos conceptos.

${ }^{14}$ Ya planteado en un trabajo clásico de Hinkelammert (1970).

${ }^{15}$ La tradición francesa de la Etnología maduró con posiciones fuertemente críticas tanto al colonialismo, como a las intervenciones aplicadas. De allí que Lévi-Strauss girara de una crítica tibia vertida en su primera Antropología estructural (1968) a una posición radicalmente opuesta: "les sciences humaines sont et seront toujours incapables de maitriser leur objet", entrevista en $\mathrm{Le}$ Monde (8/ 10/ 91; citado en Baré, 1995: 15). 
línea evolutiva en la cual las poblaciones 'occidentales' ${ }^{16}$ o desarrolladas' se encuentran en la etapa más avanzada, mientras que las menos favorecidas están ubicadas en un escalón más abajo. Esta característica tiene implicancias políticas ya que la diferencia queda naturalizada, lo cual frecuentemente no conduce a pensar en las causas de la desigual distribución de riqueza y recursos.

Así, las propuestas de desarrollo son portadoras, tanto en sus conceptos como en su accionar, del señalado mensaje 'modernizador', proponiendo transformaciones de los saberes y tecnologías locales. Las propuestas predominantes, se basan en categorías gnoseológicas emanadas y contextuadas en el pensamiento de Occidente y por tanto resultan - al gusto de los antropólogos - claramente etnocéntricas. Pero aquí uno se topa con una primera paradoja: la antropología - tanto como el desarrollo - también es fruto del pensamiento y de las necesidades de Occidente. Al respecto, James Ferguson (1997) plantea en su trabajo que las ideas evolucionistas han sido sólo superficialmente dejadas de lado por la antropología social del siglo $\mathrm{XX}$. Sugiere en cambio que la división dicotómica entre sociedades primitivas y modernas permaneció "ya no como una preocupación explícita sino como un supuesto teórico implícito" (Fabian, citado en Ferguson, 1997: 155). Señala Ferguson que "el objeto de la antropología siguió siendo definido en términos de un dualismo evolucionista que se empeñaba en distinguir entre un 'nosotros' civilizado y un 'ellos' primitivo, aún no desarrollados" (Ibíd.:156). El punto nodal del artículo de Ferguson, para entender el núcleo del conflicto entre desarrollo y antropología, es que aquél se ocupa de modernizar y modificar aquellas comunidades y grupos étnicos que los/ las antropólogos/ as estudiamos desde nuestro origen disciplinar, modificando nuestros objetos/ sujetos de estudio, lo que genera cortocircuitos entre la antropología y las practicas de desarrollo.

Pero ya de este lado del siglo XXI, todos sabemos que el colonialismo, las formas contemporáneas del imperialismo y la globalización penetran los intersticios de las culturas y sociedades más alejadas, muy a pesar de los intereses de la antropología. Por otra parte, en cualquier marco de las epistemologías que se fundamentan desde mediados del siglo XX, se reconoce que el/la antropólogo/a modifica con su presencia en el trabajo de campo a su objeto/sujeto de estudio, más allá de su voluntad e intenciones. Por tanto la antropología, aún la puramente académica, actúa modificando relaciones sociales en el ámbito bajo estudio. De allí la importancia de la reflexividad, entendida como el relevar en la etnografía las múltiples visiones de los actores en su relación con y sobre el 'otro-antropólogo', confrontadas e interpretadas a su vez por éste, desde sus explícitos intereses concretos y tradición teórica.

Una tercera cuestión a tener en cuenta es que según Ferguson (1990) el término desarrollo se refiere a dos nociones distintas, pero interrelacionadas. Por un lado define el proceso de transformación hacia una economía capitalista, moderna e industrial. Aquí incluiría nociones como las de desarrollo capitalista, desarrollo de las

${ }^{16}$ La categoría 'occidental' no es del todo precisa, sin embargo es útil para aludir a la ideología de los grupos hegemónicos europeo-norteamericanos, así como a las elites de los países 'periféricos' que en distintos momentos de la historia abogaron por cierto tipo de desarrollo ligado a la ideología del 'progreso' lineal, que propusieron paradigma de la modernidad. 
fuerzas de producción, modernización, etc. Por otro lado, según el autor, a partir de la década de los años 70 se utiliza el término desarrollo para referirse a las intervenciones tendientes a mejorar la calidad de vida y el acceso a bienes y recursos (materiales y simbólicos) de las poblaciones más vulnerables, apuntando en general a la reducción de la pobreza y haciendo énfasis con frecuencia en la disminución de la desigualdad de oportunidades para distintos grupos, sean étnicos, de género o etarios.

El desarrollo al que aquí refiero, apunta hacia la segunda acepción: el acceso a bienes y servicios sociales y la mejora de la calidad de vida de las poblaciones objetivo. Para una definición conceptual, la que brindó Sen (1981: 17-21) es suficientemente inclusiva para respetar "lo que cada grupo humano considere la mejor calidad de vida en sus propios términos; pero al mismo tiempo, proponiendo sobre unos mínimos universales que eviten caer en un relativismo excesivo" (las itálicas son mías). Sen en su modelo basado en las capacidades ${ }^{17}$ expresa la necesidad de garantizar las condiciones materiales y sociales mínimas para que las personas puedan moldear sus propias vidas, accediendo a "lo necesario para ser capaces de hacer las elecciones que consideren más oportunas según sus propios objetivos" (el énfasis es mío).

Un cuarto aspecto es la objeción de que la antropología 'para' el desarrollo no produce conocimiento científico, sino principios de aplicación que tienen que ver más con la administración y la gestión, que con la ciencia. La participación en equipos interdisciplinarios de desarrollo tiende, sobre todo en la etapa de ejecución de un proyecto, a erosionar roles de disciplinas específicas, disolviéndolas en un hacer irreflexivo ${ }^{18}$. Los momentos de lectura, actualización y debate sobre la propia práctica van siendo relegados al olvido, por las urgencias diarias. Las disciplinas sociales que deberían aportar elementos de conocimiento sobre las dinámicas socioculturales y las modificaciones que produce la puesta en práctica del proyecto - en su seno, como en la localidad - terminan absorbidas por las tareas, frecuentemente ajenas a lo planificado. Además, el tiempo que requiere un estudio clásico antropológico, con estadías prolongadas de campo, períodos de reflexión y de escritura, generalmente entra en colisión con los plazos requeridos en las diferentes etapas de las políticas públicas y el desarrollo.

Por último, uno de los problemas implícito en la ideología del desarrollo es que plantea una mayor 'integración' a la sociedad nacional de las minorías culturales y/o étnicas, para superar el 'atraso cultural', pobreza y marginalidad que los caracteriza $^{19}$. Los operadores de desarrollo no definen con precisión lo que entienden

17 ‘Capabilities approach', según la terminología de Sen (1981).

${ }^{18}$ Este dilema escapa del marco de la antropología, incluyendo a todas las disciplinas 'científicas' que involucra el desarrollo. Se puede circunscribir a los dilemas: 'la profesión versus la militancia', 'el espontaneísmo versus la planificación', 'el activismo versus el profesionalismo' (Feijoo, 1991: 30-31). En los hechos, ONGs de diferentes países de América Latina lo han tratado de resolver con mayor o menor éxito.

${ }^{19}$ Por ejemplo, durante la última epidemia de cólera a fines de los años ochenta fueron muy frecuentes las voces en la provincias del norte Argentino como Salta o Jujuy, que sostenían en 
por 'integración' puesto que desde una perspectiva socioeconómica, las poblaciones indígenas en el caso de Argentina estuvieron 'integradas', en general con empleos transitorios, precarios, sin beneficios y pésimamente remunerados, pasando por instituciones estatales modeladoras de la 'argentinidad', como la escuela, el hospital, la conscripción militar. Antes del cambio de la Constitución Nacional (1994), la 'integración' se proponía en los hechos y en la normativa en términos individuales, con la disolución de identidades y culturas no coincidentes con los parámetros de "las nacionales". Con la nueva Constitución se reconocen en el papel una serie de derechos a las etnias 'originarias', pero en los hechos sólo existen algunos avances en términos de reconocimiento simbólico de sus culturas, sin conferir autonomía, ni replantearse - al menos teóricamente-derechos colectivos (Gargarella et al., 2011), base asociativa del sujeto colectivo de proyecto. Sirva el siguiente apartado para debatir estos aspectos teóricos sobre un proyecto de desarrollo, con miradas cruzadas sobre el mismo.

\section{El proyecto Amaicha de desarrollo integrado}

El proyecto que ECIRA ${ }^{20}$ llevó a cabo en la Comunidad de Amaicha del Valle ${ }^{21}$ se inició con trabajos de campo en 1986, redactándose su Documento de Proyecto (DP) en 1987. La comunidad de Amaicha es la única comunidad indígena en Argentina que ostenta una Cédula Real ${ }^{22}$. Pertenece a la etnia de los calchaquíes, manteniendo su identidad a pesar de que perdieron la lengua ya en el siglo XVIII. Sus luchas por el territorio frente al estado colonial y luego republicano, más el interés de los pobladores por emprender 'un proyecto' incidieron fuertemente en nuestra elección. Sin embargo, el proyecto fue objetado 'por introducir formas ajenas y contrarias a la cultura y organización local', fue tildado de 'etnocéntrico', y se señaló que '... provocó tensiones y enfatizó divisiones’ (Mathwes, 1997: 247 y 248) ${ }^{23}$. En dicha tesis se anuncia una etnografía del proyecto, basándose en entrevistas a amaicheños y testimonios de miembros del equipo de proyecto. Su conclusión es negativa, aunque contradictoria. Por ejemplo, una de estas contradicciones es que Mathews en su argumentación usa explícitamente a lo largo de su manuscrito las ideas más críticas de Escobar sobre 'el desarrollo y sus efectos nefastos'. Como adelanté, las críticas al 'desarrollo económico' de Escobar quedan en un plano abstracto, pero Mathews

relación a los mayoritariamente afectados : "si dejaran de ser indios, solucionarían sus problemas" (Diario El Tribuno de Salta, 19/ 10/ 1987).

${ }^{20}$ Estudios Comparados de la Región Andina. Programa concertado entre la Universidad de Buenos Aires y el Movimento Laici per America Latina (MLAL), una ONG italiana.

${ }^{21}$ Está asentada en la parte tucumana de los Valles Calchaquíes a $180 \mathrm{~km}$. de la capital provincial. Dentro de sus límites está comprendida toda la jurisdicción de la Comuna Rural de Amaicha del Valle y parte de la de Colalao del Valle, sumando aproximadamente 100.000 hectáreas.

${ }^{22}$ Por la cual el Rey de España ('a través de sus gobernadores y Oficiales y Jefes del Ejército de su Majestad Real') en 1716 le otorga a los amaicheños unas 150.000 hectáreas (Isla 2009: 71).

${ }^{23}$ En efecto, cuando el proyecto expiraba en términos de financiamiento, una antropóloga estudiante de doctorado de la universidad de Yale realizó su trabajo de campo y luego redactó su tesis de doctorado sobre el proyecto (Mathews, 1997), que se discute abajo. 
intenta un análisis de un proyecto específico utilizando categorías generales, lo que implica un contrasentido teórico inicial. Hubiera sido más útil declarar 'todo desarrollo es negativo' y dedicarse a relevar otras cuestiones.

Expongo de manera sumaria cómo se planteó el proyecto y simultáneamente las imperfecciones del mismo, coincidentes o no con las críticas que se mencionan en la tesis citada, varias de las cuales fueron señaladas en diferentes evaluaciones, algunas públicas. En segundo lugar, presentaré las principales acusaciones de Mathews. Posteriormente expondré cómo se pensó "el sujeto colectivo de proyecto" en relación a la cultura política del noroeste argentino, y después, cuáles fueron los posibles errores de adecuación entre el diagnóstico que sirvió de base a la propuesta técnica y la cultura local.

Pero antes de iniciar esta tarea debo aclarar algunos principios teórico-metodológicos que guiaron la formulación del "sujeto colectivo de proyecto", o sea a partir de qué principios de construcción de sociedad se pensó el proyecto, más allá de que en éste se propusieran formas productivas muy concretas como el desarrollo de semilla de alfalfa. Como equipo pensamos que debíamos realizar un proyecto que incluyera al conjunto de los comuneros. Partimos del principio de que no resultaba eficaz ni interesante el esfuerzo de diseñar un proyecto sólo para un grupo de familias nativas. Además de discutir los riesgos de producir una mayor diferenciación si tomábamos beneficiarios individuales o aislados, no pensábamos la sociedad como una sociedad de individuos, sino surcada por redes y asociaciones de distinto tipo, con solidaridades que debíamos potenciar. Comenzamos a definir al futuro beneficiario como "sujeto colectivo", pues ellos asumían la identidad calchaquí y se referenciaban como "comuneros", reivindicando un territorio propio.

Se propusieron determinadas condiciones para la realización del proyecto. La primera condición fue que existiera un interlocutor colectivo frente al equipo de proyecto. Es decir, una forma organizativa que fuera más o menos representativa del conjunto de lugareños. La segunda, que esa organización comunitaria fuera legalmente constituida ${ }^{24}$ con el objetivo de equilibrar las relaciones asimétricas de poder entre el equipo externo de proyecto y las expresiones representativas de la comunidad. Con relación a la forma organizativa, expresaría inicialmente acuerdos precarios, pero era indispensable intentar representar el punto de vista particular de las diversas facciones cuya existencia intuía, aunque sin conocer aún su peso en la sociedad amaicheña. Era necesario crear una comunidad de intereses alrededor de las metas de desarrollo que se proponían y consensuaban en reuniones de amplia participación en casi todas las localidades dispersas del territorio comunal.

A su vez, como antropólogo, no se me escapaba que la juridicidad de la "asociación civil" era conferida según leyes de la sociedad nacional. En las etnografías previas a la construcción del diagnóstico se había concluido que no había ninguna 'normativa consuetudinaria' vigente que pudiera remplazar aquello, y entonces estábamos lejos de los ayllus, comunidades o sindicatos campesinos aymara o

${ }^{24}$ Se constituyó la "Asociación Civil Comunidad de Amaicha del Valle", con personería jurídica reconocida en la Provincia de Tucumán, por la Dirección pertinente. 
quechua de los Andes Centrales (con los que había estado habituado en Bolivia). Pero además, Amaicha era una comunidad relacionada en todos los planos con la sociedad nacional y el Estado, entonces debíamos enfatizar formas de juridicidad que mejoraran esas articulaciones, pensando también en la generación de formas autónomas.

En el Documento del Proyecto se dice que "fue elaborado conjuntamente con los comuneros" y tuvo como objetivo general mejorar las condiciones de vida de los mismos. La experiencia de Amaicha, como la de todos los proyectos, puede analizarse en tres grandes órdenes interrelacionados en la formulación y en la ejecución:

1. El orden ideológico-ético: los principios o macroideas que justificaron la realización de un "proyecto de desarrollo integrado" en las tierras más pobres de Tucumán, habitadas por sectores sociales marginalizados de los circuitos de produccióndistribución. Pero además, como grupo étnico portadores de una cultura e identidad, discriminada por la Estado nacional.

2. El orden político-económico: de la realización en sí de las acciones y de sus resultados en relación a los fines tácitos; el peso de lo previsto y de los imprevistos respecto a las fórmulas originales; el conjunto de las prácticas principales analizadas, clasificadas, evaluadas en sus rendimientos, en la lógica que las une y les da coherencia entre sí y con los objetivos diseñados e implícitos en los propios procesos, pero también los desplazamientos, los desajustes entre objetivos y prácticas, los procesos desatados cuyos resultados difieren de los esperados.

3. El orden metodológico-técnico: de las propuestas de desarrollo y de los procedimientos de las diferentes disciplinas que intervienen; del diagnóstico, o sea, del recorte del "problema" y su descripción pormenorizada; de la factibilidad, por lo tanto de la racionalidad (y si es posible de la medición) entre incógnitas y soluciones propuestas; de las técnicas de fabricación de objetos-mercancías y sus costos; de la construcción de un equipo de "operadores de proyecto": la definición de los perfiles, los roles, las reglas pautadas entre los miembros.

En el documento de proyecto, se enumeraban los problemas fundamentales en el siguiente orden de prioridades:

a) Progresiva pérdida de las pautas tradicionales de vida agrícola-ganadera y de la capacidad de producción. De esto deriva una descomposición entre la producción de bienes y la prestación de servicios.

b) Excesiva dependencia del estado, en especial a través de la gran cantidad de empleos públicos.

c) Alto índice de migración a los centros urbanos.

d) Déficit hídrico general en el ecosistema y, por lo tanto, insuficiencia de agua en tierras aptas para cultivo.

e) Excesiva subdivisión de la tierra con riego, lo que convierte su producción en ineficiente

f) Desertización creciente de los suelos ${ }^{25}$.

${ }^{25}$ El ecosistema se caracteriza por un equilibrio frágil, caracterizado por un proceso de degradación ambiental cuyos principales efectos son: desertización, alteración del ciclo hidrológico acentuando el déficit hídrico, erosión eólica y degradación química por efecto de salinización y alcalinización de los suelos. 
g) Inestabilidad en el régimen de tenencia de la tierra.

h) Irregularidad de títulos de posesión.

i) Debilidad de las organizaciones comunitarias.

j) Falta de capital propio y de capacidad para acceder a créditos de producción.

k) Carencia de programas educativos adecuados a las necesidades de la Comunidad

1) Insuficiencia del sistema de atención sanitaria y medicina preventiva.

m) En general, ausencia de programas de acción integrales dirigidos a mejorar el nivel de vida de la Comunidad.

n) Insuficiencia de la infraestructura de prestación de servicios básicos tales como: agua potable, energía, caminos, etc. (ECIRA, 1987)

Los Objetivos generales eran encabezados por la siguiente aclaración: "Es importante recalcar que con la implementación de este proyecto no se pretende solucionar cada uno de los problemas enunciados, sino aportar a la transformación de las condiciones básicas que permitan a la Comunidad plantearse una acción a largo plazo, lo cual sí podría llegar a ofrecer soluciones integrales" (ECIRA, 1987: 3). Los objetivos se anunciaban en el siguiente orden:

1) Recuperar la actividad productiva, como base para el crecimiento económico de la Comunidad. Para esto se implementarán programas de producción agrícola y experimentación y extensión de cultivos, lo que se acompañará con una campaña de formación para un mejor aprovechamiento del agua de riego y de los métodos de cultivo.

2) Contrarrestar la migración. Como consecuencia del objetivo anterior, se espera que diminuya el flujo migratorio de la población activa.

3) Fortalecer las organizaciones propias de la Comunidad a través de la promoción de formas de participación en las responsabilidades y las decisiones que afectan a la vida comunitaria, como una manera de contribuir a la autodeterminación.

4) Lograr el mayor consenso y participación de los integrantes de la Comunidad, en relación al proyecto y garantizar los mecanismos de continuidad una vez concluida la asistencia externa.

5) Sistematizar una metodología de intervención para este tipo de realidades y para obtener criterios de evaluación acerca de los resultados de estas intervenciones. (ibídem.)

En los puntos a) y b) del diagnóstico se adelanta, fundamentando, lo que se desarrollará en objetivos y en la propuesta técnica. Fue un planteo 'campesinista', o al menos 'agrarista': volver a introducir la producción agropecuaria basada en el trabajo familiar y en parte en el asalariado, para generar crecimiento económico, lo cual disminuiría la dependencia del empleo estatal, generando alternativas económicas para las familias y una mayor autonomía de las organizaciones comunales. Al mismo tiempo (punto c) se proponía disminuir la emigración. El éxodo de jóvenes se diagnosticaba como un grave 'problema' que el proyecto debería tender a solucionar al crear en el lugar alternativas laborales.

Ambos aspectos (el trabajo agrícola familiar y la residencia permanente) significaban importantes cambios culturales en las tradiciones locales que registraban, desde fines del siglo XIX hasta los años sesenta del siglo XX: constantes períodos de asalariamiento temporario, especialmente durante las zafras azucareras. En 
consecuencia, se había producido una tradición de migración temporaria al ingenio, la plantación, o a las ciudades aledañas para "changuear". Ambos aspectos fueron no sólo subvalorados (como tradiciones) sino mal interpretados por la dirección del proyecto. A nuestro favor debería decirse que el conjunto del proyecto fue discutido en sucesivas reuniones tanto con mujeres y hombres amaicheños, como con sus líderes y miembros de la Comisión Directiva de aquel entonces que representaba a las 3 facciones de la comunidad (Isla, 2009) y que estos temas no aparecieron como problemáticos. Por el contrario, en esas reuniones muchos amaicheños expresaron su preocupación frente a la inminencia de la emigración de sus hijos u otros parientes.

Se planeó alcanzar estos objetivos a partir de las siguientes propuestas técnicoeconómicas y organizativas:

1. Aumentar la capacidad productiva; incorporando mayor número de personas a la producción agropecuaria. Al mismo tiempo se planeaba contribuir a frenar la desertización de los suelos. El programa más fuerte orientado a este objetivo central, consistió en la siembra de 120 has de alfalfa semilla. Durante el primer año se planeaba alcanzar las 45 hectáreas sembradas, además de ponerse en funcionamiento el $90 \%$ de la infraestructura de riego (pozos de agua).

Asimismo, la maquinaria agrícola incorporada (un tractor) fue alquilada a los comuneros que la solicitaban para el trabajo de sus parcelas a precio de costo. Esto influyó de un modo no previsto sobre la generación de empleo productivo y en la ampliación de la reducida frontera agropecuaria local, ya que los beneficios indirectos no fueron evaluados en la redacción del documento base, como resultados concomitantes de las acciones que se emprenderían. Al mismo tiempo se impartió asistencia directa a los productores para la recuperación de los suelos, técnicas agropecuarias adaptadas a esas condiciones, y de forestación. Con estas acciones se esperaba generar empleo productivo, creando alternativas al empleo estatal y a la emigración laboral.

2. Fortalecer y promover organizaciones propias de la comunidad: mediante la asunción activa de los objetivos del proyecto por parte de una porción significativa de comuneros y de sus organismos. De haber en un principio solamente una Comisión Directiva, y algunos organismos de representatividad sectorial (por ej. Comisión de regantes, para el manejo del agua), la complejidad de las acciones emprendidas en términos de producción fue generando divisiones del trabajo (tractoristas, etc.) y nuevas organizaciones en la producción (grupos de parceleros, etc.). También surgieron organizaciones que representaron localidades dispersas en el territorio comunal.

3. Contribuir al autoconsumo de la comunidad. Esta meta se piensa desde la perspectiva de su fortalecimiento y protección frente al mercado de productos agropecuarios con sus altibajos nefastos para los campesinos en Argentina.

4. Promover la investigación participativa sobre identidad y memoria en los Valles Calchaquíes mediante Talleres de Historia Oral.

Así, lejos de pensar a Amaicha como una comunidad de Andes Centrales con altos niveles de autoconsumo y conservando técnicas tradicionales de producción 
(Isla, 1992), se la describió como una comunidad ligada al mercado en una región como el Noroeste de Argentina (NOA) donde el mercado de trabajo se había expandido desde fines del siglo XIX. Por eso se propuso una opción fuerte de producción agraria como el cultivo de alfalfa semilla ${ }^{26}$, un producto que debía ser vendido en un mercado oligopólico. Se suponía que esto permitiría la capitalización de un gran número de familias amaicheñas que habían aprobado esa opción al mismo tiempo que dejaría ganancias comunales, para experimentar y/o ampliar otros cultivos.

Sin embargo, para sembrar este tipo de cultivo en una zona propicia por la altitud, pero desértica y con suelos salitrosos, se requería la realización de una importante infraestructura de riego artificial. Esto implicaba la excavación de 3 pozos de más de $50 \mathrm{~m}$. de profundidad para extraer el agua con motores; los pozos debían además estar encamisados. La infraestructura de riego artificial constituía la parte dura del proyecto y de su presupuesto, pero dependía de dos condiciones: primero, que el gobierno de la provincia de Tucumán cediera la utilización de una máquina perforadora y para ello se había hecho un convenio ${ }^{27}$ firmado por todas las partes. En segundo lugar, la comunidad se comprometía a destinar trabajadores para la preparación de los terrenos para la siembra de la alfalfa. Estos trabajadores no cobrarían salario puesto que ya estaban empleados por dependencias provinciales, como Irrigación o Vialidad provincial, pero con mucha disponibilidad de tiempo.

La provincia no cumplió con el convenio ${ }^{28}$ aduciendo que sus máquinas perforadoras estaban fuera de operación, por lo que hubo que contratar a una empresa privada, lo cual incidió gravemente sobre el presupuesto, que obviamente estaba relacionado a los objetivos y acciones específicas de la formulación del proyecto. Esta fue una de las cuestiones más complicadas de resolver, pues la rigidez de la propuesta de infraestructura de riego se complementó con la propia de la entidad financiadora, que habiendo aprobado y conseguido el presupuesto, exigía que se gastara de la manera pactada.

Es sabido que es muy difícil cambiar el ciclo de proyecto cuando éste ha sido lanzado y los 'imprevistos' son inexorables. El equipo de proyecto completamente involucrado en esa dinámica, no reparó en los problemas contextuales, ni tampoco en la falta de adhesión general que al poco tiempo de su lanzamiento inspiraba la propuesta. A los meses de iniciado el proyecto, la comisión directiva se había partido, quedando solo una de las facciones, que no casualmente estaba también a cargo del proyecto por parte de la comunidad ${ }^{29}$. Pero aquí es bueno reconocer que el hecho de que las 3 facciones se sentaran, dialogaran e integraran una CD conjunta

${ }^{26}$ En Amaicha sólo se practicaba la alfalfa para forraje.

${ }^{27}$ El proyecto se comprometía a pagar los salarios de técnicos y operarios de la maquinaria y el combustible del traslado.

${ }^{28}$ Este debió ser un "imprevisto" previsto, pues ya las administraciones que había sufrido la provincia indicaban los altos niveles de deterioro administrativo y corrupción.

${ }^{29}$ El "mito de la planificación" es la descripción dada por Bennett a los imprevistos, y agrega que en un estudio del prestigioso economista Albert Hirschman sobre evaluación de proyectos, señalaba que lo más exitoso de ellos fue lo menos esperado, las "consecuencias no anticipadas", (hiding hand para Hirschman. Referencia en "Development Project Observed", citado por Bennett, 1988: 16). 
en 1988, fue producto de las tareas de mediación y persuasión que se emprendieron durante la etapa de diagnóstico y confección del Documento Base ${ }^{30}$.

Pero además de los problemas que normalmente pueden suscitarse en los equipos (disputas y rupturas) y en las financiadoras (retrasos en las cuotas) existió una división entre la propuesta de capitalización vía semilla de alfalfa y los criterios de evaluación de la experiencia por parte de algunos miembros del equipo de proyecto. En varios análisis ex ante que concluyeron en un documento, se ponderaba la factibilidad del proyecto en términos económicos. Concluidos los 4 años de implementación, en un seminario público de evaluación de la experiencia, el economista y miembro de ECIRA que había realizado las evaluaciones, anunció en su ponencia con mucha precisión el fracaso del proyecto $(1990)^{31}$ en relación a un bajo cumplimiento de las metas propuestas en su inicio. Los miembros del equipo de proyecto, más involucrados en su continuidad y menos críticos, rechazaron esa perspectiva de análisis, aduciendo que al no ser una empresa no se podía analizar desde la rentabilidad, ya que lo que se buscaba no era la ganancia.

Sin embargo, un proyecto con propuestas productivas — que además, depende de los precios del mercado para sus insumos y para la venta de su producción- debe poder ser evaluado en ese terreno. Del mismo modo, debe poder ofrecer capacidades para volverse autosuficiente y no depender para su existencia del permanente financiamiento externo, de lo contrario tiene una vida muy limitada. Y ésto fue lo que sucedió con el proyecto de desarrollo integrado en Amaicha.

Una segunda acusación de Mathews es también contradictoria: por un lado nos acusa de haber caracterizado a Amaicha como una comunidad tradicional andina, y por otro de introducir planteos tecnológicos foráneos a esa comunidad. Es posible que cierta ambigüedad entre tradición y modernidad se haya colado en nuestra mirada, que estaba alejada de diagnosticar un 'ayllu' en Amaicha, pero que sí le otorgó a la "ficción comunidad" (Isla, 2009: 53-56) un peso que en realidad no tenía.

Desde mi punto de vista, aquel no fue el error más grave, sino el hecho de haber mal entendido la presencia del Estado (nacional y provincial) en lo local, juzgándolo como un obstáculo, más que como un complemento o un piso ya instalado desde donde partir. Instalado no sólo por la fuerza intrusiva del estado nacional que existía hasta los años noventa (y quizá hasta hoy) llegando a los últimos rincones del país, sino también por la astucia y diligencia de líderes amaicheños quienes, aprovechando la ola de democratización del país del año 1983, habían logrado numerosos puestos estatales para su gente. En un seminario público de evaluación del proyecto realizado a los 3 años de ejecución y teniendo en la mano las cifras de un censo, estimé que entraban anualmente en Amaicha por lo menos 250.000 dólares (\$) vía salarios, jubilaciones y pensiones estatales ${ }^{32}$. Siendo Amaicha una comunidad indígena rural discriminada, ubicada en tierras desérticas, ese era un monto nada despre-

${ }^{30}$ Una detallada etnografía de ese proceso se encuentra en Isla, 2009.

${ }^{31}$ Giovanni Stumpo luego fue economista de la CEPAL-Chile. Esto ya lo venía anunciando (1989).

${ }^{32}$ Documento inédito presentado al Coloquio de Estudios Campesinos-Rurales de la Universidad Nacional de Salta, Argentina, 1991. 
ciable. El Estado formaba parte de la cultura local (lo sigue siendo) y por tanto de las expectativas de vida ${ }^{33}$. Es así que uno de tres de los pozos perforados en el marco del proyecto continúa ofreciendo agua, que se acopla con la que mana de otro pozo de una Dirección del Estado provincial, para generar riego de diversos cultivos en una granja experimental en territorio comunal, pero gestionada por técnicos agropecuarios de aquella dirección.

Terminado este proyecto alrededor de 1995, Amaicha-Quilmes (lugares indígenas emblemáticos de los Valles Calchaquíes) fueron comunidades seleccionadas por un megaproyecto del Banco Mundial, junto con otros dos sitios de pueblos originarios $^{34}$. El proyecto - cuyos objetivos eran similares al expuesto- comenzó a implementarse en el 2003 concluyendo en el 2007. En el lapso entre estos proyecto - como hasta el presente-, los dirigentes de Amaicha no perdieron tiempo en la ampliación de contactos y negociaciones para la obtención de recursos adicionales. No me puedo detener en este artículo en la descripción de la continuidad de prácticas clientelares y facciosas que caracterizaron esas gestiones y acciones, como cultura política extendida en diferentes sectores y clases sociales en la Argentina rural como urbana, cuestión que traté pormenorizadamente en otro lugar (Isla, 2009).

\section{La importancia de la teoría en la antropología aplicada}

El principal dilema ético que enfrenta el/ la antropólogo/a es qué derecho tiene para intervenir y producir cambios al interior de una comunidad. Este dilema por supuesto, se relaciona directamente con el relativismo cultural que es uno de los principios de la tradición disciplinar de la antropología. Esto, a su vez, está relacionado con dos suposiciones: la primera, esbozada más arriba, apunta a considerar que de no haber 'intervención vía desarrollo', el/la antropólogo/a inserto/a en una comunidad extraña a la propia podría mantener una "neutralidad valorativa" sin operar modificaciones. En realidad, la 'ilusión' de neutralidad es una construcción posttrabajo de campo, obra del estilo y las formas que se imprimen a la escritura etnográfica. Esto quedó demostrado cuando la familia del eminente Malinowski, publicó su diario de campo años después de su muerte. Allí uno se podía sumergir en los sentimientos y valores contradictorios e íntimos, que inspiró su larga relación con los nativos de las Trobriand, eludidas en la escritura de sus etnografías clásicas. Una reflexión epistemológica no puede desconocer que la presencia del antropólogo/a en una comunidad, localidad o cualquier tipo de grupo humano, genera efectos aunque sean mínimos, más allá de su voluntad.

La segunda suposición se basa en la presunción de que el desarrollo es una intervención totalmente dirigida desde afuera, contraria a la voluntad e interés de los actores beneficiarios. Esto sería el producto de pensar a la comunidad local en cuestión, como un grupo ahistórico, sin agencia y entonces sin capacidad de expresar por sí mismo sus necesidades, intereses y conocimientos. Además, este supuesto

\footnotetext{
${ }^{33}$ Para una discusión detallada de las controversias véase Isla (2005).

${ }^{34}$ Pulmari en la provincia de Neuquén, habitado por Mapuches; y Finca Santiago en la provincia de Salta, habitada por Kollas.
} 
simplista no tiene en cuenta que la población local puede desear cierto tipo de cambios en sus condiciones de vida y que la antropología, en tanto ciencia social, puede contribuir para que la intervención requerida o propuesta tenga en cuenta las características y necesidades de la población. Se debería así dejar de pensar en el 'otro' como un ser lejano, despegado de 'nosotros'. El 'otro' forma parte de un sistema macro en el que no está libre de las influencias de 'occidente' y posiblemente desee algunos de los cambios propuestos desde fuera. Siguiendo la utopía de D'Amico Samuels (1991: 68) "si la antropología ha de ser descolonizada, debe comenzar por situarse a sí misma, a los que la practican y a los sujetos de sus investigaciones, dentro del mismo espacio físico y temporal y con referencia a las jerarquías políticas, económicas y sociales del mismo mundo".

La antropología contemporánea no ofrece un único camino para resolver estos problemas y tensiones. Pero una de las vertientes que resulta más productiva es la que pone el acento en la centralidad del actor para relevar, valorar, analizar la sociedad y la cultura y el mismo proyecto. $\mathrm{O}$ sea, reconocer al actor como centro de la escena, para desde allí responder a la frecuente contradicción entre "discurso" y "acción" acudiendo a la noción de "práctica" (Ortner, 1984: 149-151). La noción de "prácticas" de Ortner ${ }^{35}$ trata de resolver ese frecuente hiato, al entender que la expresión del actor no puede quedar solamente en sus palabras por más abundantes que sean, sino que se expresa también en sus acciones cotidianas, más allá de la conciencia o intencionalidad puesta en las mismas. En este paradigma se denominan 'acciones performativas' aquellas representaciones extralingüísticas que 'significan' y conforman 'practicas'. Sólo un trabajo de campo intensivo logra reconstruir "las diferentes prácticas". Esta vertiente a su vez, no niega la existencia de un 'sistema' que actúa como contexto y que condiciona las prácticas, sino que le asigna la misma importancia heurística que la acción del actor. Se presupone que la 'subjetividad' del actor se articula con la posición que ocupan en la estructura social o 'sistema' de manera particular, según también la coyuntura o el momento histórico.

La noción de "prácticas" permite situarse fuera del terreno de la antropología aplicada, para redefinirla desde una antropología política. A su vez, dándole a ésta un nuevo sentido en el que la ética y punto de observación sobre la participación sociopolítica de los beneficiarios y promoción de cambios, involucra también al autor como 'sujeto de acción y de estudio' y donde las acciones de desarrollo deben ser cuidadosamente consensuadas con los intereses, necesidades, formas organizativas y posibles propuestas de los beneficiarios ${ }^{36}$.

De esta manera, debería profundizarse la relación entre política y desarrollo en el análisis específico de los mecanismos decisionales de la localidad que estamos estu-

${ }^{35}$ Ortner (1984) frecuentará a Bourdieu y a Giddens para fundamentar su concepción, relacionándolos con los resultados teóricos de las tradiciones de la antropología social. Reconociendo la importancia de la antropología simbólica o interpretativa de Geertz y Turner para inscribir su propuesta teórica.

${ }^{36}$ Muchas veces estas "soluciones" son rechazadas de plano desde el equipo de proyecto, pues están formuladas desde una diferente lógica cultural. Sin embargo, suelen contener valoraciones agudas sobre la historia y el porvenir de la comunidad local. 
diando. La mayoría de los investigadores tiende a creer — por los tiránicos tiempos de la financiación - que la única manera en que una sociedad decide sus acciones democráticamente es mediante la regla de la mayoría. El reconocimiento de otras formas de representación es condición necesaria para proponer cualquier alternativa de cambio. Registrarlas, sin embargo, lleva bastante tiempo, pues dichos mecanismos se encuentran relacionados con el sistema político y el ejercicio y distribución del poder en general. Es decir, a los liderazgos formales e informales, a los procedimientos manifiestos y a las formas encubiertas del ejercicio del poder; todos estos, aspectos básicos de la cultura política ${ }^{37}$.

Es fundamental, dirá Ortner, "...la centralidad de la dominación dentro del marco teórico contemporáneo, o por lo menos dentro del segmento del marco que nosotros hemos focalizado aquí. Estoy persuadida como muchos autores que penetrar en las relaciones sociales asimétricas es penetrar en el corazón de cualquier sistema dado..." (1984: 157). Campo de fuerzas entonces, donde reconocemos y subrayamos sus pugnas, asimetrías y relaciones de dominación; pero también "... los patrones de cooperación, reciprocidad, y solidaridad constituyen el otro lado de la moneda..." (ibídem). Estos 'patrones de cooperación' a menudo aparecen ligados a identidades étnicas/ territoriales, constituyendo la base de un sujeto colectivo que debe ser reconocido en su extensión y límites en el trabajo de campo específico. Pero que además, debe conceptualizarse como sujeto de derecho, si partimos de la base de que su autonomía no sólo queda en un reconocimiento simbólico en clave multicultural, como elocuentemente criticó Díaz Polanco (2006) en su recorrido por los fundamentos del liberalismo y su pasaje al neoliberalismo.

El proyecto debe generar lo que desde hace unos años se comenzó a denominar con el neologismo 'empoderamiento' (empowerment); o sea, el reconocimiento del conocimiento local y de las capacidades allí instaladas para el fortalecimiento del sujeto colectivo, beneficiario de las acciones. Así, se propende a robustecer las solidaridades vecinales, barriales, comunales, las redes que podríamos llamar horizontales, y que confieren autonomía, consolidando las identidades grupales. Al fortalecer las organizaciones de los movimientos sociales por su base, se intensifica su capacidad de interlocución con gobiernos y estados, su capacidad de demanda, negociación, reclamo y resistencia. Su capacidad no sólo de recibir los beneficios de política públicas, sino de convertirse como meta en un corrector y forjador de las mismas.

\section{Reflexiones finales}

Después de participar como antropólogo en un puñado de proyectos de desarrollo asumiendo diferentes roles, en diagnósticos y diversas consultorías sobre políticas públicas, concluyo en señalar tres campos controvertidos que nos acechan cuando entramos en el meollo de la 'aplicación' de la antropología. A ellos —que trato a

${ }^{37}$ Que defino como "terreno de prácticas y discursos verbales, campos de simbolización e identificación, relacionados a expresiones de poder (y por ende a formas de autoridad y jerarquía) conscientes y/o no conscientes de los actores, que se manifiestan en relaciones sociales en el espacio público y en el privado" (Isla, 2000: 210). 
continuación- llamaré: el campo disciplinar-académico, el campo de la política y el campo de la ética.

Respecto al primero, los desafíos provienen del hecho de que el mundo del desarrollo nos sumerge como antropólogos/as indefectiblemente en el mar turbulento de la transdisciplina, cumpliendo además roles que tanto la formación en antropología, como su trayectoria disciplinar, en general no contemplan. Por ejemplo, en el caso tratado de Amaicha, debí asumir - por momentos- el rol de codirector, cumpliendo acciones en administración y contabilidad, en un proyecto en marcha. Este proyecto como otros, en los que participé con roles más acotados, exigen una enorme versatilidad para comprender otros lenguajes técnicos, guiados por otras lógicas disciplinares. Tener que contribuir a encontrar metas y un lenguaje común con ingenieros agrónomos, abogados, geólogos o economistas, sumados a técnicos de especialidades tan diversas como las mencionadas, implica un desafío que va más allá de un abordaje desde la interdisciplina. Aunque en este tipo de intersección disciplinar de mayor proximidad disfruté del intercambio con sociólogos cuantitativos, con quienes realicé encuestas (basadas en cuestionario) diseñadas, monitoreadas y analizadas desde metodologías cualitativas, o incluso desde etnografías.

En este sentido, un buen diseño de proyecto plasmado en metas, objetivos, presupuesto acorde, criterios de evaluación, y un buen diagnóstico del 'problema', ayudan a encontrar acuerdos operativos, o consensos más acabados, entre las disciplinas en juego, al estar definido qué se espera de cada una de ellas en relación a los objetivos.

La tabla de salvación será la solidez teórica-metodológica en la formación disciplinar que ayudan al antropólogo que por momentos se siente desbordado, a no perder su norte. El peligro reside en que el/la antropólogo/a mareado/a por los 'imprevistos' que siempre suceden en la ejecución de proyectos, o por los plazos acotados de las financieras o seducido por otras lógicas, abandone -o se distraiga - de las trayectorias teóricas que sustentan y modelan la disciplina.

Uno de los aspectos que también inciden en estas incertidumbres es que existen muchos 'informes' de proyectos 'exitosos', redactados con un estilo panegírico de la experiencia. Simultáneamente, hay pocas sistematizaciones veraces publicadas y menos aún etnografías de proyectos, que permitan extraer balances y conclusiones, y así poder avanzar en el campo teórico-metodológico.

El campo de la política nos sitúa en un escenario cuyo dictum reza que 'ninguna intervención es neutra'. Pero además de esta sentencia general y de amplio acuerdo en la disciplina, las tareas de diagnóstico que inician el diseño de un proyecto, interpelan al antropólogo/a desde por lo menos tres esquinas, que se intensificarán si uno permanece - con el rol que sea - durante la ejecución del proyecto. Una primera es la de los 'futuros beneficiarios': cómo hacemos para que participen en la elaboración del diagnóstico y en la construcción de metas y objetivos, que se plasmarán en el 'documento-propuesta', partiendo de la base de que para que cualquier política social o proyecto de desarrollo comunitario (vecinal/ barrial) sea medianamente exitoso, debe contar con el deseo y la aprobación de gran parte de los futuros beneficiarios. No obstante en nuestro trabajo de campo encontraremos 
grupos facciosos que disputan recursos materiales y simbólicos. El terreno siempre será más o menos sinuoso por los conflictos y las heterogéneas posiciones; a su vez, 'la población-objetivo' es parte de una cultura, una sociedad y de las instituciones estatales. De allí concluyo que la identificación y análisis de la cultura política local es imprescindible.

Una segunda esquina de interpelación a nuestro trabajo, proviene justamente de los agentes de las instituciones estatales con ramificaciones en lo 'local' o aquellas encargadas de aplicar la política social bajo evaluación. En innumerables ocasiones esos agentes pueden constituir un obstáculo o por el contrario favorecer la ejecución del proyecto o de la política social.

Por fin, somos interpelados desde el organismo financiador, sea del tercer sector, privado o estatal. Mediar y armonizar los intereses de todos estos actores para alcanzar consensos operativos por lo general es una tarea ciclópea, donde la política en su versión de aproximar intereses y puntos de vista disímiles, así como mitigar conflictos, es central.

Por último, el tercer campo controvertido y problemático que anuncié se refiere a los dilemas éticos que asisten a la disciplina, como por ejemplo, la aceptación del principio de universalidad de los derechos humanos, que colisiona con el de relativismo cultural sobre el que se basa la antropología. Otro dilema clásico versa sobre si es posible además de estudiar Otras culturas, dirigirlas u orientarlas hacia lo que en la metrópoli se denomina, 'civilización' — o 'integración al Estado nacional', que antes citamos-, dilema central en las tradiciones antropológicas metropolitanas, así como un debate algo desplazado o no asumido en las periféricas. Ello supone la idea de que la responsabilidad por el colonialismo cabe únicamente a las tradiciones metropolitanas, constituyéndose en los adalides de la civilización. Sin embargo, las élites que construyeron las repúblicas del siglo XIX en América, estaban completamente imbuidas de aquellos conceptos valorativos que llevaron, a la ejecución de varios genocidios de los pueblos originarios, para edificar el Estado Nación moderno, como por ejemplo en el caso argentino. Esos valores impregnan el sentido común de la sociedad donde el antropólogo nativo se ha criado, socializado y educado. Por lo que constituye un ejercicio heurístico indispensable de la antropología sumergirse en ese sentido común para bucear y desenmascarar esos valores con ayuda de la teoría crítica. Además, una etnografía profunda con el grupo social en cuestión tiende a resolver dilemas éticos, puesto que al rescatar la visión del 'Otro', se encontrarán las propias perspectivas del 'Nosotros'. En variadas experiencias se registra que lo más dificultoso de la transacción entre el equipo profesional-técnico y los beneficiarios, es el debate para expurgar ideas de la sociedad dominante, incrustadas y reivindicadas como soluciones mágicas no sólo por la prédica del conocimiento 'experto', sino también por el propio 'sujeto colectivo del proyecto'. Es indispensable el respeto por el 'Otro', pero no hasta el punto de 'exotizarlo' desde la creencia con apariencia de inocencia de que tal sujeto está fuera de la influencia de los procesos hegemónicos de Occidente.

Por ello, se debe poner atención al tipo de inserción del sujeto del proyecto en la sociedad global. Esa inserción no debe ser valorada únicamente desde la estructura 
socioeconómica, analizando cómo participan en el mercado de trabajo, sino también desde el campo político-simbólico de los actores, como parte de su cultura política. Esto es, teniendo en cuenta también las políticas de identidad de los actores. Un buen apoyo para identificar estas observaciones lo constituye la antropología política desde donde debemos vigilar la relación siempre controvertida entre la antropología social y el amplio mundo del desarrollo.

\section{Referencias bibliográficas}

ARCHETTI, Eduardo; STÖLEN, Kristi Anne

1975 Explotación Familiar y Acumulación de capital en el campo argentino. Buenos Aires: Siglo XXI.

BARE, Jean-François

1995 "La question de application de la anthropologie en France", en J-F. Baré (comp.), Les applications de l'anthropologie. Un essai de réflexion collective depuis la France. Paris: Karthala.

BARTOLOME, Leopoldo

1969 Nam'Kom: una comunidad toba periurbana. Provincia de Chaco, Roque Sáenz Peña: mimeo.

BENNETT, John W.

1988 "Anthropology and Development: The Ambiguous Engagment", en: J. W. Bennett y J. Bowen (comps.), Production and Autonomy: Anthropological Studies and Critiques of Development. Monographs in Economic Anthropology $\mathrm{N}^{\circ}$ 5, Univ. Press of America.

BILBAO, Santiago

1975 La Familia en San José del Boquerón (Provincia de Santiago del Estero). Buenos Aires: Fichas de CICSO.

CORDEU, Edgardo

1967 Cambio cultural y configuración ocupacional en una comunidad toba. MirafloresChaco: mimeo.

CORDEU, Edgardo; SIFFREDI, Alessandra

1971 De la algarroba al algodón. Movimientos milenaristas del Chaco Argentino; Edit. Juárez, Buenos Aires.

D'AMICO SAMUELS, Deborah

1991 "Undoing fieldwork: persons, political, theoretical and methodological implications", en Harrison, F. (Ed.,), Decolonizing Anthropology, Washington: American Anthropological Association.

DÍAZ POLANCO, Héctor

2006 Elogio de la Diversidad. Globalización, multiculturalismo y etnofagia. México: Siglo XXI.

ECIRA

1987 Documento de Proyecto de Desarrollo Integral de Amaicha del Valle. Tilcara, Jujuy, Argentina: Documento de Trabajo $\mathrm{N}^{\circ} 1$. 
ESCOBAR, Arturo

1991 Anthropology and the Development Encounter: The Making and Marketing of Development Anthropology. American Ethnologist, No.18 (4): 16-40.

1995 Encountering Development: The Making and unmaking of the Third World, New Jersey: Princeton University Press.

1997 “Antropología y desarrollo", Revista Internacional de Ciencias Sociales, 154: http://www.unesco.org/issj/rics154/escobarspa.html

FEIJÓO, María

1991 "Con los pies en el barro. Reflexiones sobre la metodología de los microproyectos a partir de las experiencias de monitoreo", en Martínez Nogueira, R. (Comp.) La Trama Solidaria. Pobreza y Microproyectos de Desarrollo Social. Buenos Aires: Gadis.

FERGUSON, James

1990 The anti-politics machine: Develoment, Depoliticization and Bureaucratic power in Lesotho. Minneapolis: University of Minnesota Press.

1997 "Anthropology and its evil twin: 'Development' in the constitution of a discipline", en: Cooper, F. y R. Packard (Eds.), International Development and the Social Sciences: essays on the history and politics of knowledge. Berkeley-London: University of California Press.

GARGARELLA, Roberto (Ed.)

2011 La Constitución en 2020. 48 propuestas para una sociedad igualitaria. Buenos Aires: Siglo XXI.

GONZÁLEZ CASANOVA, Pablo (Ed.)

1969 Sociología de la Explotación. México: Siglo XXI.

GRILLO, Ralph

1985 “Applied Anthropology in the 1980s: retrospect and prospect”; en: Grillo, R. (Ed.), Social Anthropology and Development Policy. London: Travistock.

1997 "Discourses of Development: The view from Anthropology" en: Grillo, R. y R. Stirrat (Eds.), Discourses of Development: anthropological perspectives, Oxford: Berg.

HERMITTE, Esther; IÑIGO CARRERAS, Nicolás; ISLA, Alejandro

1994 [1971] Estudio sobre la situación de los aborígenes de la Provincia del Chaco y politicas para su integración a la sociedad nacional, (tres volúmenes), Posadas: Ed. de la Universidad Nacional de Misiones.

HINKELAMERT, Franz (Ed.)

1970 Ideologías del desarrollo y dialéctica de la historia. Buenos Aires: Nueva Universidad, Universidad Católica de Chile y Editorial Paidós.

ISLA, Alejandro

1992 “Dos Regiones, un Origen. Entre el Silencio y la Furia”, en Isla (comp.), Sociedady articulación en las Tierras Altas Jujeñas. Crisis terminal de un modelo de desarrollo. Buenos Aires: ECIRA. 
2000 "Los apoyos de Bussi. Valores domésticos, espacios públicos en el presente tucumano", en Svampa (Comp.), Desde abajo. La transformación de las identidades sociales. Buenos Aires: Edit. Biblos.

2005 "Cultura política y desarrollo. Controversias en torno a un proyecto de producción comunal”, en Isla - Colmegna (Comps.), Política y Poder en los procesos de Desarrollo. Buenos Aires: Edit. De las Ciencias.

2009 Los usos políticos de la identidad. Criollos, Indígenas y Estado. Buenos Aires: Editorial Araucaria.

LÉVI-STRAUSS, Claude

1968 Antropología Estructural, Buenos Aires: Eudeba.

MATHWES, Patricia Delia

1997 Between the Andes and Buenos Aires: The Politics of Ethnic and National Identity in Rural Tucumán, Argentina, Ph.D. Dissertation in Yale University.

MONREAL, Pilar; GIMENO, Juan Carlos

1998 "El poder del desarrollo: antropología de un encuentro colonial", en P. Monreal, y J.C. Gimeno. (Eds.), La controversia del desarrollo: Criticas a la antropología. Madrid: Los Libros de la Catarata.

NICANDRO CRUZ, César

2001 "La construcción de conceptos en ciencias sociales: Una discusión sobre el desarrollo humano y la gobernabilidad democrática. Entrevista a Oscar Oszlak". Magazine DHIAL, 17, Barcelona: Instituto Internacional de Gobernabilidad, Barcelona.

ORTNER, Sherry

1984 "Theory in Anthropology since the Sixties". Society for Comparative Study of Society and History, Vol. 26: 126-166.

RATIER, Hugo

1972 Villeros y villas miseria. Buenos Aires: Centro Editor de América Latina.

RIBEIRO, Darcy

1972 Las Américas y la civilización: proceso de formación y causas del desarrollo desigual de los pueblos americanos, Buenos Aires: Centro Editor de América Latina.

SEN, Amartya

1981 Poverty and famines: an essay on entitlement and deprivation. Oxford: Oxford University Press.

STAVENHAGEN, Rodolfo

1969 Las clases sociales en las sociedades agrarias. México: Siglo XXI.

STUMPO, Giovanni

1989 "Informe sobre la auditoría de Amaicha", 07/ 1990; Documento Interno CADIF y "Evaluación ex-ante y bienestar colectivo. El enfoque del análisis costo beneficio social". San Salvador de Jujuy: Documento de Trabajo, ECIRA. 
1990 Tiene sentido hacer evaluaciones ex-ante? Repensando Amaicha cuatro años después. Ponencia inédita. Seminario Amaicha, evaluaciones y debates. Jujuy: Tilcara.

WOLF, Eric

1967 Tribal and peasant economies: readings in economic anthropology, edited by George Dalton, Garden City, N.Y: Published for the American Museum of Natural History [by] the Natural History Press.

1972 Las luchas campesinas del siglo XX; Madrid: Siglo XXI. 